\title{
Redesain Dan Analisa Kelayakan PLTMH 25 KW Desa Susuan Karangasem Bali
}

\author{
D. N. T. Budiantara ${ }^{1}$, I. N. S. Kumara ${ }^{2}$, I. A. D. Giriantari ${ }^{3}$ \\ Submission: 05-06-2019, Accepted: 22-08-2019
}

\begin{abstract}
The electricity necessary in Indonesia increases from year to year. In Indonesia the use of fossil power plants is still widely used. Water energy itself is an alternative to replace fossil fuels in general, one of which is Micro Hydro Power. This research was made to identify PLTMH in Sususan Karangasem Village that can be revitalized (rebuilt) through measurement and calculation of the potential of water resources using the flow duration curve method with a probability of exceeding $80 \%$. To analyze the feasibility of PLTMH, financial analysis is carried out namely Net Present Value (NPV), Internal Rate Ratio (IRR), Payback Period $(P P)$ and Benefit Cost Ratio (BCR). The results of the analysis found that the potential of the Karangasem PLTMH is $25.18 \mathrm{kWh}$ with electricity generation per year at $220.577 \mathrm{kWh} /$ year and electricity $B P P=R p$. 774.- per $k W h$. From the results of the analysis, PLTMH Desa Susuan Karangasem can be said to be feasible for revitalization.
\end{abstract}

Keywords: renewable energy, microhydro, revitalization, flow duration curve, financial analysis, NPV, IRR, CBR, PBP

Intisari- Kebutuhan akan energi listrik Indonesia selalu meningkat dari tahun ke tahun. Di Indonesia penggunaan pembangkit listrik tenaga fosil masih banyak digunakan. Energi air sendiri merupakan alternatif untuk menggantikan bahan bakar dari fosil secara umum, salah satunya Pembangkit Listrik Tenaga Mikro Hidro. Penilitian ini dibuat untuk mengindentifikasi PLTMH di Desa Sususan Karangasem dapat di revitalisasi (dibangun kembali) melalui pengukuran dan perhitungan potensi sumber daya air dengan metode flow duration curve dengan probabilitas terlampaui $80 \%$. Untuk menganalisis kelayakan PLTMH dilakukan analisis finansial yakni Net Present Value (NPV), Internal Rate Ratio (IRR), Payback Period (PP) dan Benefit Cost Ratio (BCR). Hasil dari analisis didapatkan potensi dari PLTMH Karangasem saat ini yakni 25,18 kWh dengan pembangkitan listrik per tahun sebesar $220,577 \mathrm{kWh} /$ tahun dan BPP listrik = Rp. 774.- per $\mathrm{kWh}$. Dari hasil analisis, PLTMH Desa Susuan Karangasem dapat dikatakan layak untuk dilakukan revitalisasi.

Kata Kunci: Pembangkit Listrik Tenaga Mikro Hidro (PLTMH), Analisis Hidrologi, Analisis Ekonomi Energi, Revitalisasi

\section{PENDAHULUAN}

Pertumbuhan penduduk tiap tahun semakin meningkat

${ }^{1}$ Mahasiswa, Program Studi Pascasarjana Teknik Elektro Universitas Udayana, Banjar Sampiang, INDONESIA (HP: 081237166053; e-mail: dewabj.tri3@ gmail.com)

${ }^{2,3}$ Staf Pengajar, Program Studi Pascasarjana Teknik Elektro Universitas Udayana, Jln. P.B Sudirman Denpasar, INDONESIA 80234 (telp: 0361-223797, e-mail: satya.kumara@unud.ac.id, dayu.giriantari@unud.ac.id)

D. N. T. Budiantara: Redesa sebesar $1,49 \%$ dari total jumlah penduduk 257 juta jiwa pada tahun 2015 [1]. Pertumbuhan penduduk ini selalu dibarengi dengan pertumbuhan ekonomi masyarakat Indonesia, begitu pula dengan kebutuhan listrik masyarkat, tercatat hingga akhir tahun 2015 rasio elektrifikasi listrik Indonesia adalah sebesar 88,3\%. Dan diakhir tahun 2019 pemerintah menargetkan rasio elektrifikasi sebesar 97,4\%. Untuk dapat mencapai target tersebut pemerintah harus membangun infrastruktur pembangkit listrik diberbagai daerah di Indonesia. Saat ini pembangkit listrik tenaga fosil masih mendominasi untuk mengejar defisit energi listrik, serta mengejar pemerataan infrastruktur di tiap daerah agar teraliri listrik, tercatat Minyak $(41,4 \%)$, Batubara $(29,4 \%)$, Gas $(23,6 \%)$, EBT $(5,6 \%)$ [2]

Sumber energi baru terbarukan di Indonesia jumlahnya cukup banyak, yakni sumber daya air. Tercatat tenaga air menghasilkan $16,6 \%$ total listrik dunia dan $70 \%$ dari seluruh energi terbarukan, dan diperkirakan akan naik $3,1 \%$ per tahun sampai 25 tahun ke depan [3]. Tren peningkatan ini memberikan sentiment positif terhadap pembangunan EBT kedepan, salah satunya Pembangkit Listrik Tenaga Mikro Hidro (PLTMH). Pembangkit EBT di Bali juga masih jauh di bawah target. Pada tahun 2014, porsi EBT baru mencapai $1 \%$ [ref paper ICITEE 2014, cek di bagian akhir] dan sekarang ini kondisinya tidak jauh berubah. Sehingga ke depan perlu dilakukan pembangunan pembangkit EBT baru atau melakukan revitalisasi terhadap pembangkit EBT yang mengalami kerusakan.

Desa Susuan atau Desa Pekraman Susuan terletak di pulau Bali bagian timur tepatnya di kelurahan Karangasem, Kecamatan Karangasem, yang berjarak sekitar 2,5 Km dari Kota Amlapura. Desa Susuan memiliki luas wilayah kurang lebih 1,64 Km2. Jumlah penduduk Desa Pekraman Susuan yakni sekitar 300 Kepala Keluarga (KK) atau 1067 jiwa yang sebagian penduduknya bermata pencaharian sebagai petani, peternak, pedagang, buruh, PNS, TNI, Polri dan swasta. Dari berbagai profesi yang disebutkan tersebut, 30\% mata pencaharian masyarakat Desa Susuan adalah bertani [4].

PLTMH Karangasem berdiri sejak tahun 2007, namun pada tahun 2010 PLTMH ini tidak beroperasi. Salah satu faktor tidak beroperasinya pembangkit tersebut antara lain minimnya sumber daya manusia dan tata kelola dari unit usaha yang mengelola PLTMH.

Tujuan penulisan paper ini adalah untuk meredesain PLTMH Susuan Karangasem dan melakukan analisa investasi. Informasi ini dapat dijadikan rujukan untuk memperbaiki PLTMH Karangasem sehingga dapat beroperasi kembali sebagai pembangkit listrik terbarukan dan menjadi bagian dari upaya pencapaian target $23 \%$ energi terbarukan pada tahun 2025.

$$
\text { p-ISSN:1693 - 2951; e-ISSN: 2503-2372 }
$$




\section{Pembangkit Listrik Tenaga Mikro Hidro}

\section{A. Debit Andalan}

Debit sungai yang merupakan data pokok untuk perencanaan pusat listrik tenaga air, untuk itu harus diukur secara teliti dan dalam jangka waktu yang sepanjang mungkin. Pengukuran yang dilakukan Pengukuran secara manual menggunakan pelampung: Kecepatan rata-rata dari aliran sungai pada suatu bagian dari penampangnya diukur, kemudian dikalikan dengan luas penampang pada bagian itu. Hasil perkalian luas penampang dengan kecepatan tersebut adalah debit sungai, dengan persamaan sebagai berikut [5]:

$$
\mathrm{Q}=\mathrm{A} \times \mathrm{V}
$$

Dimana:

$\mathrm{Q}=$ debit $\left(\mathrm{m}^{3} / \mathrm{dt}\right)$

$\mathrm{V}=$ Kecepatan rata-rata $(\mathrm{m} / \mathrm{dt})$

$\mathrm{A}=$ luas rata-rata $\left(\mathrm{m}^{2}\right)$

Pada saluran irigasi sungai dengan tipe trapezium dapat dihitung dengan rumus:

$$
\mathrm{A}=\mathrm{y} *(\mathrm{~B}+\mathrm{my})
$$

\section{Dimana:}

$\mathrm{A}=$ Luas penampang saluran $\left(\mathrm{m}^{2}\right)$

$\mathrm{y}=$ Tinggi air $(\mathrm{m})$

$\mathrm{B}=$ Lebar bawah saluran $(\mathrm{m})$

$\mathrm{m}=$ Lebar sisa sisi saluran $(\mathrm{m})$

\section{B. Ketinggian Air (Head)}

Untuk menentukan ketinggian air yang mengalir pada penstock, dilakukan dengan menggunakan software Google Map®.

\section{Prinsip Kerja PLTMH}

Prinsip kerja PLTMH yaitu memanfaatkan beda tinggi dan jumlah debit air per detik yang ada pada aliran atau sungai. Air yang mengalir dengan kapasitas tertentu disalurkan dengan ketinggian tertentu menuju turbin. Air tersebut akan jatuh pada turbin dimana turbin itu sendiri akan menerima energi air tersebut dan mengubahnya menjadi energi mekanik berupa putaran. Poros yang berputar tersebut kemudian ditransmisikan ke generator dengan menggunakan kopling. Dari generator akan dihasilkan energi listrik yang akan dimasukkan ke sistem kontrol arus listrik sebelum dialirkan ke pelanggan [6].

$$
\mathrm{P}=9,81 \times \eta \times \mathrm{Q} \times \mathrm{H} \mathrm{kW}
$$

Dimana :

$\mathrm{P}=$ Daya dibangkitkan $(\mathrm{kW})$

$\mathrm{Q}=$ Debit air $(\mathrm{m} 3 / \mathrm{dt})$

$\mathrm{H}=$ Ketinggian $(\mathrm{m})$

$\eta=$ Efisiensi dari system $(\%)$

$9,81=$ Konstanta gravitasi bumi
Jadi untuk menentukan produksi energi listrik per tahunnya dapat dihitung dengan rumus [7]:

Energi per tahun $=\mathrm{P}($ net $\mathrm{kWh}) \times$ Jam kerja PLTMH selama setahun $\mathrm{x}$ CF $(\mathrm{kWh})$

Di mana:

CF : Capacity factor (\%)

Jam kerja PLTMH $\quad$ : 8760 jam selama setahun

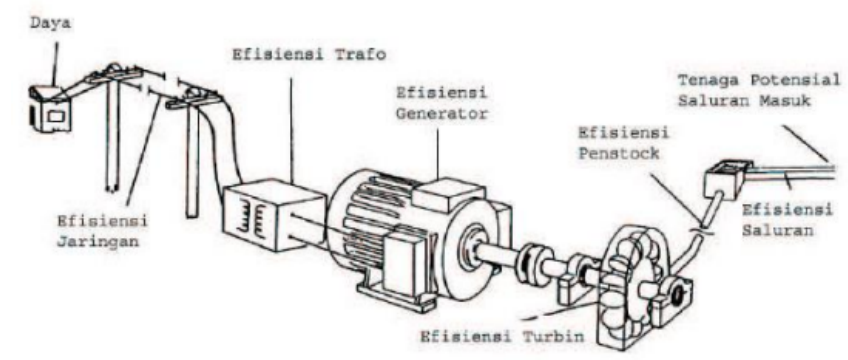

Gambar 1: Prinsip Kerja PLTMH [7]

\section{Analisis Ekonomi}

Analisis ekonomi dilakukan untuk menentukan besaran biaya yang akan keluar dan yang akan masuk untuk manajemen PLTMH. Komponen dari perhitungan yakni [8]:

a. Biaya pembangunan PLTMH

b. Biaya operasional \& pemeliharaan

c. Biaya penjualan pembangkitan (BPP)

Biaya modal penjualan $=$ Biaya Investasi

$\overline{\text { Produksi listrik selama masa ekonomis }(\mathrm{kWh})}$

$\mathrm{BPP}=$ Biaya modal penjualan - BPP Nasional [9]

d. Cash flow PLTMH per tahun

E. Analisis Kelayakan

Untuk menentukan kelayakan revitalisasi pembangunan PLTMH digunakan beberapa metode sebagai berikut:

\section{a. Payback Period (PBP)}

Metode pemulihan investasi (Payback period) merupakan metode analisis kelayakan investasi untuk menilai jangka waktu (tahun) pemulihan seluruh modal yang diinvestasi dalam suatu proyek. Dengan persamaan yang digunakan yaitu [10]:

Pendekatan rumus:

$\mathrm{PBP}=($ Investment Cost $) /($ Annual CIF $) \times$ umur ekonomis PLTMH (tahun)

Dimana:

PBP : Payback period

Investment cost : Besar biaya investasi

Annual CIF : Nilai pendapatan pertahun (selama masa ekonomis PLTMH) 


\section{Kriteria kelayakan:}

1. Pengembalia cepat dari umur ekonomis (layak)

2. Pengembalian lama dari umur ekonomis (tidak layak)

\section{b. $\quad$ Net Present Value (NPV)}

Merupakan metode analisis keuangan yang memperhatikan adanya perubahan nilai uang karena faktor waktu, proyeksi arus kas dapat dinilai sekarang (periode awal investasi) melalui pemotongan nilai dengan faktor penurangan yang dikaitkan dengan baiaya modal [10].

$$
N P V=\sum_{t-1}^{T} \frac{C t}{(1+r)^{t}}-C 0
$$

Dimana:

NPV : Net present value (dalam Rupiah)

$\mathrm{Ct} \quad$ : Arus kas per tahun pada periode $\mathrm{t}$

C0 : Nilai investasi awal pada tahun ke 0

(dalam Rupiah)

$\mathrm{r} \quad=$ Suku Bunga atau discount rate $($ dalam \%)

Kriteria kelayakan:

1. NPV positif $>0$ maka proyek layak untuk dilaksanakan.

2. NPV negatif < 0 maka proyek tidak layak untuk dilaksanakan.

\section{c. Internal Rate of Return}

Metode tingkat balikan internal (Internal Rate of Return $I R R$ ) merupakan metode penilaian kelayakan proyek dengan menggunakan perluasan metode nilai sekarang. Proyek layak diterima apabila IRR lebih besar dari suku bunga di bank atau tingkat pengembalian untuk suatu proyek investasi (Minimum Attractive Rate of Return -MARR) [10]

IRR

$$
=\mathrm{I}_{(\mathrm{r})}+\frac{N P V(r)}{N P V(r)-N P V(t)} \times\left(\mathrm{I}_{(\mathrm{t})}-\mathrm{I}_{(\mathrm{r})}\right)
$$

Dimana:

IRR

: NPV bunga rendah

NPV (t) : NPV bunga tinggi

I(r) : Suku bunga rendah

I(t) : Suku bunga tinggi

Kriteria kelayakan:

1. IRR > suku bunga yang ditetapkan, maka proyek layak untuk dilaksanakan.

2. IRR < suku bunga yang ditetapkan, maka proyek tidak layak untuk dilaksanakan

\section{d. Benefit Cost Ratio (BCR)}

BCR merupakan perbandingan nilai semua manfaat terhadap nilai semua biaya pada waktu yang sama [11].

$$
B C R=\sum_{i=t}^{i=n} \frac{(B t)}{(1+i)^{t}}: \sum_{i=t}^{i=n} \frac{(C t)}{(1+i)^{t}}
$$

Dimana:

$\begin{array}{ll}\mathrm{BCR} & : \text { Benefit cost ratio } \\ \mathrm{B}_{(\mathrm{t})} & : \text { Keuntungan tiap tahun } \\ \mathrm{C}_{(\mathrm{t})} & : \text { Biaya tiap tahun }\end{array}$

$\mathrm{C}_{(\mathrm{t})} \quad$ : Biaya tiap tahun
Kriteria kelayakan:

: Tahun (waktu berjangka)

Tingkat bunga

1. $B C R \geq 1$ maka proyek layak untuk dilaksanakan,

2. $\mathrm{BCR}<1$ maka proyek tidak layak untuk dilaksanakan.

F. Pengelolaan PLTMH

Melalui PERMEN ESDM No. 12 Tahun 2016, menyatakan pada pasal 34 ayat 2, "Usaha jasa penunjang tenaga listrik dilaksanakan oleh badan usaha yang meliputi [12]:

a. Badan Usaha Milik Negara

b. Badan Usaha Milik Daerah

c. Badan Usaha Swasta

d. Koperasi

Yang berbadan hukum Indonesia dan berusaha dibidang jasa penunjang tenaga listrik. Isi dari Permen ESDM ini jelas memberikan keleluasaan untuk mendorong pihak swasta dan koperasi dalam membantu sector ketersediaan energi di Indonesia.

\section{Metode PENELITIAN}

Pada penulisan paper ini, data yang digunakan diambil dari Dinas PU Kabupaten Karangasem yang berlokasi di Jl. Nenas, Amlapura, Bungaya Kangin, Bebandem, Bungaya Kangin, Kabupaten Karangasem. Adapun data pendukung didapat melalui dari web BPS Data yang digunakan yakni:

1. Data daftar sungai Karangasem

2. Data debit rata-rata sungai yang dikelola oleh Pemerintah Kabupaten Karangasem.

3. Data curah hujan Bali

Skenario yang dipaparkan pada paper ini yakni, biaya pokok pembangkitan (BPP) yang didapat Rp. 137/ kWh. Jika biaya modal penjualan listrik ini dikurangi dengan BPP Kepmen ESDM No. 1772 K/20/MEM/2018 yakni Rp 911/ kWh [12], maka nilai jual listrik dari PLTMH Karangasem (BPP) yakni Rp. 774 /kWh. Dengan asumsi capacity factor yang dipakai $100 \%$, artinya ketersediaan air (hidrologi) setempat dapat diasumsikan melimpah [13].

Pada perhitungan cash in flow, disimulasikan bahwa biaya penyusutan dimasukan pada akhir arus kas masuk bersih. Memasukan biaya penyusutan pada akhir perhitungan cash flow ini untuk mengurangi aliran kas keluar seperti pajak penghasilan, sehingga pengelola PLTMH mendapatkan keuntungan yang optimal sebelum masa ekonomis PLTMH berakhir [14].

\section{ANALISIS DAN PEMBAHASAN}

Desa Susuan atau Desa Pekraman Susuan terletak di pulau Bali bagian timur tepatnya di kelurahan Karangasem, Kecamatan Karangasem, yang berjarak sekitar 2,5 Km dari Kota Amlapura. Desa Susuan memiliki luas wilayah kurang lebih 1,64 $\mathrm{Km}^{2}$, dengan batas wilayah sebelah utara Lingkungan Gelumbang, batas sebelah selatan Lingkungan Taman II, sebelah barat Lingkungan Juuk Manis dan batas D. N. T. Budiantara: Redesain Dan Analisa Kelayakan PLTMH 25 KW...
p-ISSN:1693 - 2951; e-ISSN: 2503-2372 
sebelah timur Lingkungan Belong. Jumlah penduduk Desa Pekraman Susuan yakni sekitar 300 Kepala Keluarga (KK) atau 1.067 jiwa yang sebagian penduduknya bermata pencaharian sebagai petani, peternak, pedagang, buruh, PNS, TNI, Polri dan swasta. Dari berbagai profesi yang disebutkan tersebut, 30\% mata pencaharian masyarakat Desa Susuan adalah bertani.

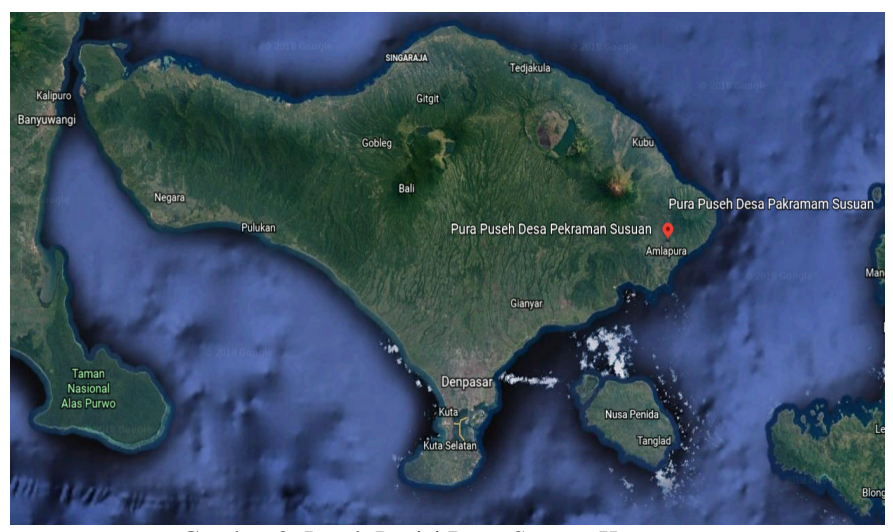

Gambar 2: Letak Posisi Desa Susuan Karangasem

PLTMH Karangasem merupakan unit pembangkit mikihidro skala kecil pertama di Bali, dimana unit pembangkit ini memanfaatkan aliran sungai Janga sebagai energi utama. Sungai Janga terdiri dari beberapa anak sungai, tercatat pada Dinas PU Karangasem, sungai Janga terdiri dari Tukad Janga Cau Jasi I, Tukad Janga Cau Jasi I, Tukad Janga Cau Jasi II, dan Tukad Janga Cau Jasi III. Pertemuan dari ketiga sungai ini membuat sungai Janga memiliki debit air yang cukup besar dibandingkan dengan sungai-sungai lain di Kabupaten Karangasem.

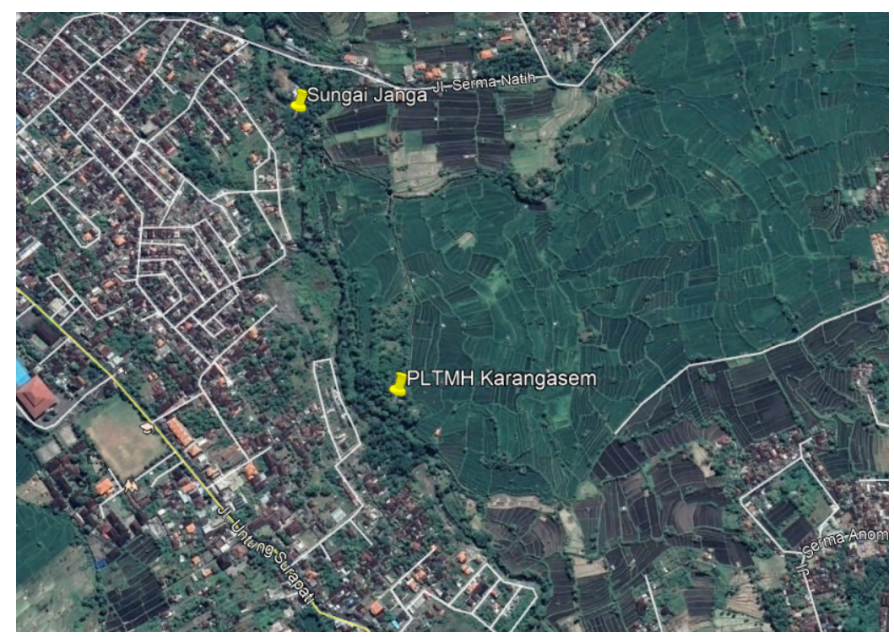

- Gambar 3: Lokasi PLTMH Karangasem

Untuk menentukan potensi dari saluran irigasi menuju reservoir PLTMH dilakukan perhitungan menggunakan pelampung, dimana pelampung diletakan diatas permukaan air dan jarak awal dilakukan per 1 meter kemudian dilakukan pencatatan menggunakan stopwatch (Gambar 4). Dari hasil perhitungan kecepatan aliran irigasi existing sungai Janga, perlu diolah kembali untuk mendapatkan debit aliran di sepanjang saluran irigasi menuju PLTMH yakni dengan menghitung luasan penampang dari saluran irigasi yang berbentuk trapesium. Lebar saluran bawah 1,1 meter, slopping (kemiringan) dan ketinggian air berdasarkan hasil pengukuran lampangan $55 \mathrm{~cm}$ (Gambar 5).

TABEL I

DEBIT BULANAN SEPANJANG TAHUN 2017

\begin{tabular}{|l|r|}
\hline \multicolumn{1}{|c|}{ Bulan } & $\begin{array}{c}\text { Debit Rata-rata } \\
\text { (lt/dt) }\end{array}$ \\
\hline Januari & 1.676 \\
\hline Febuari & 2.396 \\
\hline Maret & 1.502 \\
\hline April & 1.559 \\
\hline Mei & 1.621 \\
\hline Juni & 1.655 \\
\hline Juli & 1.674 \\
\hline Agustus & 1.455 \\
\hline September & 1.356 \\
\hline Oktober & 1.282 \\
\hline November & 1.385 \\
\hline Desember & 7.219 \\
\hline
\end{tabular}

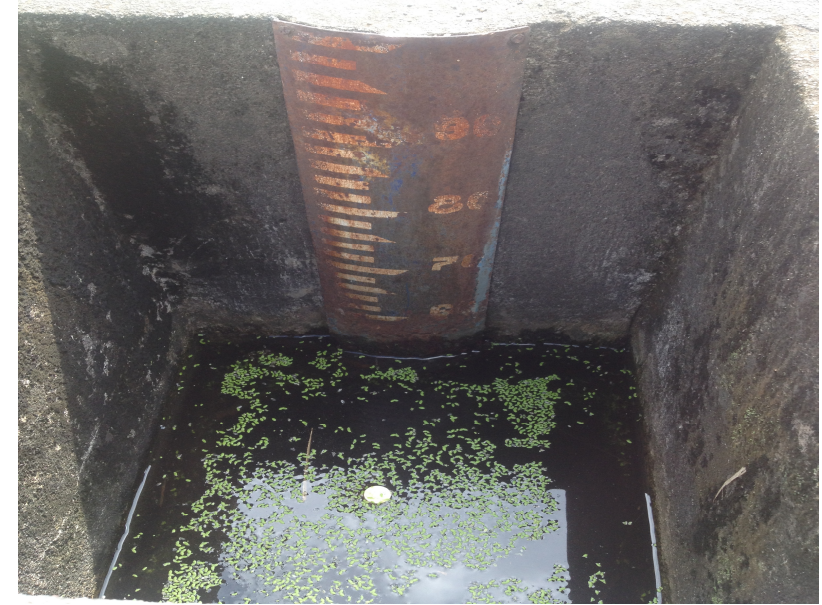

Gambar 4: Tinggi Air di Saluran Irigasi Sungai Janga

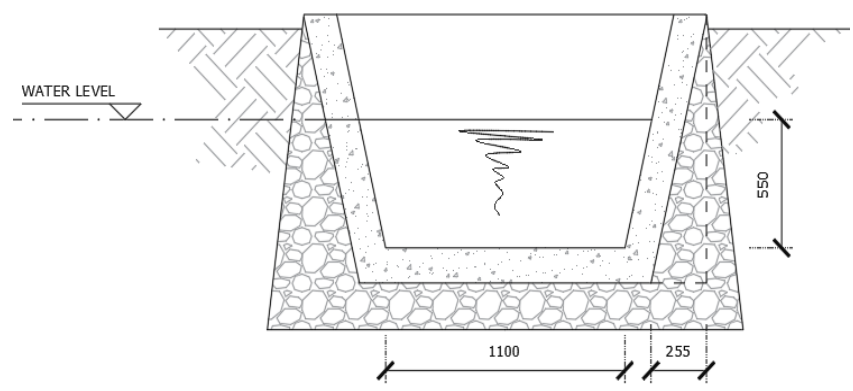

Gambar 5: Trapezium Saluran Irigasi Sungai Janga

TABEL II

PENGUKURAN KECEPATAN ALIRAN IRIGASI SUNGAI JANGA 


\begin{tabular}{|c|c|c|c|}
\hline $\begin{array}{c}\text { Lebar } \\
\text { Sungai } \\
\text { (meter) }\end{array}$ & $\begin{array}{c}\text { Jarak } \\
\text { Tempuh } \\
\text { (meter) }\end{array}$ & $\begin{array}{c}\text { Waktu } \\
\text { (detik) }\end{array}$ & $\begin{array}{c}\text { Kecepatan } \\
\text { (m/detik) }\end{array}$ \\
\hline 0,15 & 1 & 3,68 & 0,27 \\
\hline 0,3 & 1 & 3,79 & 0,26 \\
\hline 0,45 & 1 & 3,1 & 0,32 \\
\hline 0,6 & 1 & 3,09 & 0,32 \\
\hline 0,75 & 1 & 3,29 & 0,30 \\
\hline 0,9 & 1 & 3,88 & 0,26 \\
\hline 1,05 & 1 & 3,22 & 0,31 \\
\hline 1,2 & 1 & 3,79 & 0,26 \\
\hline 1,35 & 1 & 3,59 & 0,28 \\
\hline 1,5 & 1 & 3,2 & 0,31 \\
\hline \multicolumn{2}{|c|}{ Rata-rata } & $\mathbf{3 , 4 6}$ & $\mathbf{0 , 2 9}$ \\
\hline
\end{tabular}

$$
\begin{aligned}
& \mathrm{A}=\mathrm{y} *(\mathrm{~B}+\mathrm{my}) \\
& \begin{aligned}
\mathrm{A}=0, & 55 *(1,1+0,255 * 0,55) \\
& =0,55 * 1,24 \\
& =1,24 \mathrm{~m}^{2}
\end{aligned}
\end{aligned}
$$

nilai berdasarkan manfaat suatu investasi

Aspek ekonomi pada penelitian ini memaparkan besaran biaya investasi pada bagunan sipil (Tabel III) dan biaya investasi mekanikal dan elektrikal (Tabel IV).

TABELIII

BIAYA INVESTASI REHABILITASI BANGUNAN SIPIL PLTMH

\begin{tabular}{|l|r|}
\hline \multicolumn{1}{|c|}{ Biaya Komponen Bangunan Sipil } & \multicolumn{1}{c|}{ Nilai (Rp) } \\
\hline Pekerjaan Persiapan & 9.969 .292 \\
\hline Kolam Penenang & 28.500 .000 \\
\hline Perbaikan Saluran Pembawa & 36.192 .927 \\
\hline Renovasi Bangunan PLTMH & 35.000 .000 \\
\hline Total (Rp) & 109.662 .219 \\
\hline Grand Total Pekerjaan Sipil (Rp) & $\mathbf{1 0 9 . 6 6 2 . 0 0 0}$ \\
\hline
\end{tabular}

TABEL IV

BIAYA INVESTASI REHABILITASI MEKANIKAL-ELEKTRIKAL PLTMH

Jadi luas penampang basah dari saluran irigasi sungai Janga $1.24 \mathrm{~m} 2$. Untuk mendapatkan besaran debit air yang melewati penampang trapesium yakni:

$\mathrm{Q}=\mathrm{A} \times \mathrm{V}$

$\mathrm{Q}=1,24 \mathrm{~m}^{2} \times 0,29(\mathrm{~m} / \mathrm{dt})$

$=0,36 \mathrm{~m}^{3} / \mathrm{dt}$ atau 360 liter/ detik

Untuk menghitung head tinggi rendahnya posisi power house dengan bak penenang (reservoir) digunakan aplikasi Google Earth didapat titik koordinat:

- Bak penenang (Reservoir): 8²6’31.38” S dan 115 '36'14.20" E

- Power house : 8²6’33.10" S dan 115 '36'13.41” E

Dengan hasil perhitungan menggunakan Google Earth didapat:

Head $($ meter $)=149$ (elevasi reservoir $)-137$ (elevasi power house)

$$
=12 \text { meter }
$$

Dengan besar debit air sebesar $0,36 \mathrm{~m} 3 / \mathrm{dt}$ dan head sebesar 12 meter serta nilai effisiensi turbin yang diambil yakni $70 \%$, maka didapatkan besaran daya output yang dihasilkan oleh PLTMH yakni:

$\mathrm{P}_{\mathrm{t}}=9,8 \times \mathrm{Q} \times \mathrm{H} \times \eta_{\mathrm{g}} \times \eta_{\mathrm{t}}$

$\mathrm{Pt}=9,8 \times 0 ., 36 \times 12 \times 0,85 \times 0,7$

$\mathrm{Pt}=25,18 \mathrm{~kW}$

\section{B. Analisis Ekonomi}

Analisis finansial dilakukan untuk mengetahui kelayakan ekonomis suatu pembangunan. Dimana model evaluasi dari analisis finansial disini mempertimbangkan beberapa aspek

\begin{tabular}{|l|r|}
\hline \multicolumn{1}{|c|}{$\begin{array}{c}\text { Biaya Komponen Mekanikal- } \\
\text { Elektrikal }\end{array}$} & Nilai (Rp) \\
\hline Turbin air + Generator (Kap. 25 kW) & 128.700 .000 \\
\hline Panel proteksi (70 A) & 15.540 .000 \\
\hline Panel sinkronisasi & 31.250 .000 \\
\hline Transformer (30 kVA) & 98.500 .000 \\
\hline Total (Rp) & 273.990 .000 \\
\hline Grand Total Pekerjaan Mekanikal - & $\mathbf{2 7 3 . 9 9 0 . 0 0 0}$ \\
Elektrikal (Rp) & \\
\hline
\end{tabular}

TABEL V

BIAYA INVESTASI PLTMH KARANGASEM

\begin{tabular}{|l|r|}
\hline \multicolumn{1}{|c|}{$\begin{array}{c}\text { Biaya Komponen PLTMH } \\
\text { Karangasem }\end{array}$} & Harga (Rp) \\
\hline Pekerjaan Sipil & 109.662 .000 \\
\hline Mekanikal-Elektrikal & 273.990 .000 \\
\hline Total & 383.652 .000 \\
\hline PPN 10\% & 38.365 .200 \\
\hline Grand Total (Rp.) & $\mathbf{4 2 2 . 0 1 7 . 2 0 0}$ \\
\hline
\end{tabular}

Produksi energi per tahun dapat dihasilkan dari perhitungan hasil perkalian jumlah daya dibangkitkan $(\mathrm{kW})$ dengan waktu yang diperlukan (t) selama satu tahun (8760 jam) dengan capacity factor (CF). Secara teori dapat dipergunakan persamaan: 
Energi per tahun $=\mathrm{P}($ net $\mathrm{kWh}) \times$ Jam kerja PLTMH selama setahun $\mathrm{x} \mathrm{CF}(\mathrm{kWh})$

$$
\begin{aligned}
& =25,18 \times 8760 \times 70 \% \\
& =154.404 \mathrm{kWh} / \text { tahun }
\end{aligned}
$$

Hasil produksi listrik PLTMH per tahun 154,404kWh/ tahun dengan capacity factor pembangkit diasumsikan sebesar $70 \%$ yang merupakan pertimbangan dimana debit air yang mengalir tidak selalu konstan sepanjang tahun

$$
\begin{aligned}
\text { Biaya modal penjualan } & =\frac{422,017,200}{25,18 \times 70 \% \times 172.000} \\
& =136,66=R p 137 / \mathrm{kWh}
\end{aligned}
$$

\begin{tabular}{|c|c|c|c|}
\hline Jabatan & $\begin{array}{l}\text { Jumlah } \\
\text { Personil }\end{array}$ & $\begin{array}{c}\text { Gaji per Bulan } \\
\text { (Rp) }\end{array}$ & $\begin{array}{c}\text { Biaya } \\
\text { Operasional } \\
\text { per Bulan (Rp) }\end{array}$ \\
\hline Kepala Teknisi & 1 & 2.500 .000 & 2.500 .000 \\
\hline $\begin{array}{l}\text { Teknisi/ } \\
\text { Operator }\end{array}$ & 1 & 2.355 .045 & 2.355 .045 \\
\hline \multicolumn{3}{|c|}{ Total Biaya Operasional per Bulan (Rp) } & 4.855.045 \\
\hline \multicolumn{3}{|c|}{ Total Biaya Operasional per Tahun (Rp) } & 58.260 .540 \\
\hline
\end{tabular}

BPP PLTMH= 911- $137=$ Rp. 774/ kWh

TABEL VI

UPAH TENAGA PENGELOLA PLTMH SESUAi UMR KaRANGASEM

TABEL VII

BIAYA MAINTENANCE PLTMH

\begin{tabular}{|l|r|}
\hline \multicolumn{1}{|c|}{ Biaya Operasional \& Maintenance } & Biaya (Rp) \\
& \\
\hline Penggantian oli mesin & 1.040 .000 \\
\hline Penggantian fan belt & 150.000 \\
\hline Penggantian bearing & 150.000 \\
\hline Pemberian grease & 200.000 \\
\hline Inventaris kantor & 500.000 \\
\hline Total Biaya OM per Tahun (Rp) & $\mathbf{2 . 0 4 0 . 0 0 0}$ \\
\hline
\end{tabular}

Analisis ekonomi dilakukan untuk menentukan biaya yang akan dikeluarkan untuk membangun kembali PLTMH Karangasem. Komponen dari perhitungan cash flow dari
PLTMH Karangasem diantaranya:

- Produksi PLTMH per tahun

- Capacity factor PLTMH : $70 \%$

- BPP PLTMH Karangasem (Rp) : 774/ kWh

- Biaya investasi (Rp) : 422.017 .200

- Bunga bank : $9 \%-12 \%$

- Biaya operasional per tahun (Rp) $\quad 58.260 .540$

- Biaya pemeliharaan per tahun (Rp) : 2.040 .000

- Biaya penyusutan per tahun: $\frac{422.017 .200}{20 t h n}=\mathrm{Rp}$. 21.100.860

- Dimana: 20 tahun merupakan umur ekonomis dari PLTMH

Pada tahun pertama berdirinya PLTMH dapat dilihat pada perhitungan pendapatan per tahun sebagai berikut:

Pendapatan bruto per tahun $=$ Rp. $774 / \mathrm{kWh} \times(25,18 \mathrm{~kW} \times$ $70 \%$ x 8760 jam)

$\begin{array}{ll} & =\text { Rp. 170.801.379 } \\ \text { Pada tahun pertama berdirinya PLTMH Karangasem }\end{array}$ dipredisikan akan mendapatkan cash flow Rp. 57.352.447

C. Analisis Finansial

Dari analisis kelayakan finansial PLTMH Karangasem dapat dilihat pada Tabel VIII, dimana capacity factor yang digunakan 70\%: Hasil analisis finansial kelayakan PLTMH Karangasem didapatkan NPV pada bunga 12\%: Rp. 6.373.670, NPV bunga rendah 9\% Rp. 101.527.232. Dari nilai NPV yang didapatkan bernilai positif, artinya proyek PLTMH layak. Pada IRR didapatkan bunga $12,2 \%$, nilai bunga ini diatas rate yang ditetapkan yakni 12\%, maka proyek PLTMH layak. Pada perhitungan PBP didapatkan pengembalian nilai investasi terjadi pada 7 tahun 3 bulan, nilai pengembalian yang cukup pendek dan baik untuk dilakukan investasi. Sedangkan pada perhitungan BCR didapatkan rasio 0,95\%, nilai rasio ini masih dibawah nilai 1 , ini berarti investasi PLTMH tidak layak. Dari hasil semua perhitungan finansial pada CF 70\%, memberikan keuntungan secara finansial namun belum memberikan manfaat kepada pihak pengelola PLTMH (Tabel VIII).

D. Analisis Sensitifitas

Pada perhitungan finansial kelayakan pada CF $70 \%$ menunjukan NPV yang layak, IRR yang layak, PBP yang layak, namun pada perhitungan BCR masih dibawah rasio yang diharapkan, artinya PLTMH ini belum memberikan manfaat kepada pihak pengelola. Agar PLTMH dapat memberikan keuntungan secara finansial kepada pihak pengelola, maka dibuatkan analisis sensitifitas, dimana capacity factor (CF) yang digunakan yakni 100\%. Asumsi capacity factor yang dipakai $100 \%$, artinya ketersediaan air (hidrologi) setempat dapat diasumsikan melimpah [15].

Dari hasil analisis elastisitas didapatkan analisis finansial pada PLTMH pada CF $100 \%$, NPV positif (layak), IRR diatas bunga yang ditetapkan yakni $17,65 \%$ (layak), PBP yang pendek yakni $4,35 \%$ (layak) dan rasio BCR diatas 1 yakni 
1,61 (layak).Maka revitalisasi PLTMH Karangasem pada CF $100 \%$ dan harga jual listrik Rp. 774/ kWh bisa dikatakan layak untuk dilaksanakan (Tabel IX).

TABEL VIII

ANALISIS FINANSIAL PLTMH KARANGASEM PADA CF 70\%

\begin{tabular}{|c|c|}
\hline Komponen Biaya & Nilai \\
\hline Produksi energi listrik (kWh/ tahun) & 154.404 \\
\hline Harga energi listrik $(\mathrm{Rp} / \mathrm{kWh})$ & 774 \\
\hline Pendapatan bruto per tahun $(\mathrm{Rp})$ & 119.560 .965 \\
\hline \multicolumn{2}{|l|}{ Biaya operasional \& maintenance } \\
\hline Biaya gaji $(\mathrm{Rp})$ & 58.260 .540 \\
\hline Biaya Pemeliharaan (Rp) & 2.040 .000 \\
\hline Penyusutan $(\mathrm{Rp})$ & 21.100 .860 \\
\hline Nilai pendapatan per tahun (Rp) & 38.159 .565 \\
\hline \multicolumn{2}{|l|}{ Pajak pph 21} \\
\hline Penghasilan $<50 \mathrm{jt}$ & 1.907 .978 \\
\hline \multicolumn{2}{|l|}{ Penghasilan > $50 \mathrm{jt}-250 \mathrm{jt}$} \\
\hline Cash flow (Rp) & 36.251 .587 \\
\hline Cash in flow + Penyusutan (Rp) & 57.352 .447 \\
\hline NPV bunga tinggi (12\%) & 6.373.670 \\
\hline NPV bunga rendah $(9 \%)$ & 101.527.232 \\
\hline IRR (\%) & 12,20 \\
\hline PBP (Tahun) & 7,36 \\
\hline BCR (Rasio) & $\mathbf{0 , 9 5}$ \\
\hline
\end{tabular}

E. Struktur Organisasi Pengelolaan PLTMH

Secara struktur organisasi, nantinya divisi pengelolaan PLTMH Karangasem ini akan didampingi oleh Kabag Aneka Jasa. Dimana Kabag Aneka Jasa akan dipimpin oleh Manajer KUD yang akan menjalankan fungsinya memberikan arahan terkait peningkatan mutu dari SDM maupun pengelolaan PLTMH. Sedangkan Ketua Koperasi menjalankan fungsinya yakni menjalin kerja sama dengan pihak PT. PLN (Persero), tokoh masyarakat dan pengguna jasa, serta bertanggung jawab terhadap pengelolaan, yang dikemudian hari divisi pengelolaan PLTMH Karangasem dapat terus berkerlanjutan dalam melaksanakan tugasnya dibidang operasional dan pemeliharaan unit PLTMH (Gambar 6).

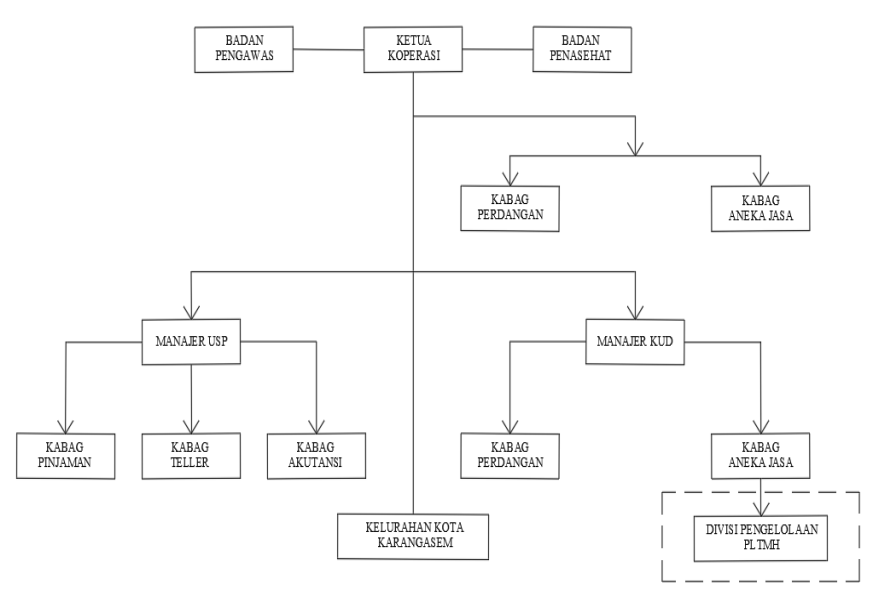

Gambar 6 Rencana Struktur Organisasi Koperasi Karangasem dengan Penambahan Divisi Baru

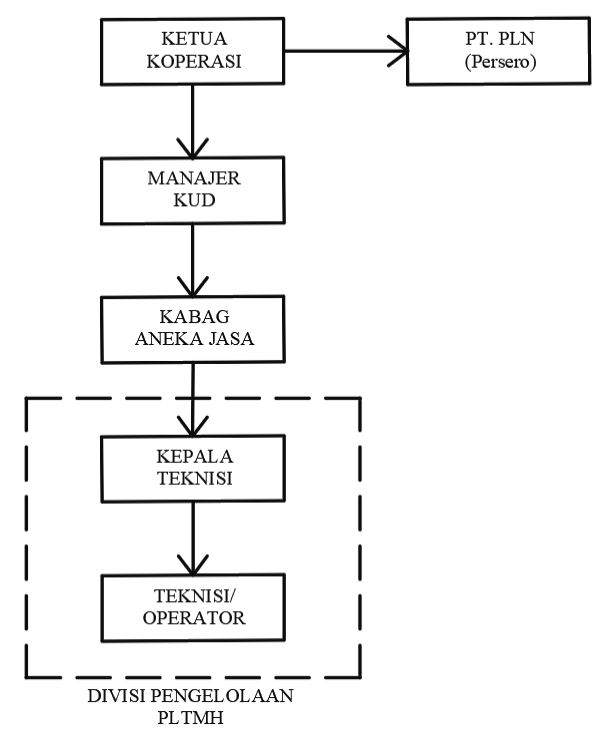

Gambar 7 Struktur Organisasi PLTMH Karangasem Baru

\section{Kesimpulan}

Potensi debit air PLTMH Karangasem saat ini masih ada. Dilihat dari besarnya debit air di saluran intake sungai Janga yakni $0,36 \mathrm{~m}^{3} / \mathrm{dt}$ dengan potensi pembangkitan daya listrik $25.18 \mathrm{~kW}$.

Harga jual listrik (BPP) yang nantinya dapat direkomendasikan kepada pihak penjual PT. PLN (Persero) yakni Rp. 774/ kWh pada CF 70\%. Pada tabel 4 dapat dilihat ananlisis finansial NPV yang layak, IRR yang layak, PBP yang layak, namun pada perhitungan BCR masih dibawah rasio yang diharapkan, artinya PLTMH ini belum memberikan manfaat kepada pihak pengelola. Agar PLTMH dapat memberikan keuntungan secara finansial kepada pihak pengelola, maka dibuatkan analisis sensitifitas. Dari hasil analisis sensitifitas pada Tabel IX, PLTMH dikatakan layak

D. N. T. Budiantara: Redesain Dan Analisa Kelayakan PLTMH 25 KW...

p-ISSN:1693 - 2951; e-ISSN: 2503-2372 
secara finansial yakni pada CF 100\%, NPV positif (layak), IRR diatas bunga yang ditetapkan yakni $17,65 \%$ (layak), PBP yang pendek yakni $4.35 \%$ (layak) dan rasio BCR diatas 1 yakni 1,61 (layak).

Rancangan pengelolaan PLTMH Karangasem agar pengoperasiannya optimal dan berkelanjutan perlu dibuatkan sebuah divisi baru atau unit kerja di dalam Koperasi Karangasem. Dimana unit kerja ini ditangani oleh ketua teknisi 1 orang dan asisten teknisi berjumlah 1 orang (Gambar 7).

\section{REFERENSI}

[1] PT. PLN (Persero). Statistik PLN 2015. Indonesia, 2015.

[2] S. Kumara, Nyoman. "Telaah Terhadap Program Percepatan Pembangunan Listrik Melalui Pembangunan PLTU Batubara 10.000 MW”. Majalah Ilmiah Teknologi Elektro. ISSN 2503-2372. Universitas Udayana, Agustus 2012.

[3] N. S. Kumara, W. G. Ariastina, I. W. Sukerayasa and I. A. D. Giriantari, "On the potential and progress of renewable electricity generation in Bali". 2014 6th International Conference on Information Technology and Electrical Engineering (ICITEE), Yogyakarta, 2014, pp. 1-6. doi: 10.1109/ICITEED.2014.7007944

[4] PT. PLN (Persero). Sustainability Report PLN 2015. Indonesia, 2015.

[5] Disbud Karangasem. http://disbud.karangasemkab.go.id/blog/databudaya/desa-pakraman-susuan/. [Online]

[6] G. Yasa, "Analisis Pengelolaan Pembangkit ListrikTenaga Mikrohidro di Desa Susuan Karangasem Secara Tekno Ekonomis". Tesis, Manajemen Energi, Teknik, Universitas Udayana, 2011.

[7] Indarto, Juwono dan Rispiningtati. "Kajian Potensi Sungai Srinjing untuk Pembangkit Listrik Tenaga Mikrohidro (PLTMH) Brumbung di Kabupaten Kediri”. Jurnal Teknik Pengairan, 2012, Vol. 3 No. 2 Desember: 174-184.

[8] Ismail dan Supriono. "Analisis Ekonomi Energi Perencanaan Pembangkit Listrik Tenaga Mikrohidro Merangun (Desa Merangun, Kec. Nanga Taman, Kab. Sekadau)”. Jurnal ELKAHA, Vol. 5, No. 1 Maret 2013.

[9] Tambunan dan Setiabudy. "Analisis Kelayakan Pembangunan Pembangkit Listrik Tenaga Mikrohidro (PLTMH) di Desa Nyomplong Bogor". Fakultas Teknik, Universitas Indonesia. 2014.

[10] Sudargana, Karnoto, Hari Nugroho, "Studi Kelayakan dan Perancangan Pembangkit Listrik Tenaga Mikrohidro di Dukuh Pekuluran Kec. Doro Kab. Pekalongan”, Jurnal Rotasi, Vol 3, No2, April 2005.

[11] Eiji, Ohno. "Cost-benefit Analysis of Small Hydroelectric Generation Project utilizing Resident Volunteers". Faculty of Urban Science, Meijo University. Japan. 2016.

[12] Pemanfaatan Sumber Energi Terbarukan untuk Penyediaan Tenaga Listrik. PERMEN ESDM. No. 12 Tahun 2017

[13] Besaran Biaya Pokok Penyediaan Pembangkitan PT. Perusahaan Listrik Negara (Persero) Tahun 2017. KEPMENESDM No. 1772 $\mathrm{K} / 20 / \mathrm{MEM} / 2018$.

[14] Suparyawan, DPD; Kumara, INS; Ariastina, Wayan G. "Studi Perencanaan Pembangkit Listrik Mikrohidro Di Desa Sambangan Kabupaten Buleleng Bali”. Majalah Ilmiah Teknologi Elektro, [S.1.], v. 12, n. 2. ISSN 2503-2372. Bali. 2013

[15] Kumara, D. P. D. Suparyawan, W. G. Ariastina, W. Sukerayasa and I. A. D. Giriantari, "Microhydro powerplant for rural area in Bali to generate green and sustainable electricity". International Conference on Smart Green Technology in Electrical and Information Systems (ICSGTEIS), pp. 113-117, doi: 10.1109/ICGTEIS.2014.7038741. Kuta, 2014.

[16] Purnama, Ady. Studi Kelayakan Pembangunan Pembangkit listrik Tenaga Mikro Hidro Studi Kasus PLTMH Minggir pada Saluran Irigasi Minggir di Padukuhan Klagaran Desa Sedangrejo Kecamatan Minggir Kabupaten Sleman. Jurnal UNSA. Jilid 10. No. 15 Oktober 2011 
TABEL IX

ANALISIS SENSITIFITAS FINANSIAL PLTMH

\begin{tabular}{|c|c|c|c|c|}
\hline \multirow{2}{*}{ Komponen Biaya } & \multicolumn{4}{|c|}{ Capacity Factor } \\
\hline & $100 \%$ & $80 \%$ & $70 \%$ & $65 \%$ \\
\hline Produksi energi listrik per tahun (kWh) & 220.577 & 176.461 & 154.404 & 143.375 \\
\hline Harga energi listrik (Rp/ kWh) & 774 & 774 & 774 & 774 \\
\hline Pendapatan bruto per tahun (Rp) & 170.801 .379 & 136.641 .103 & 119.560 .965 & 111.020 .896 \\
\hline \multicolumn{5}{|l|}{ Biaya Operasional \& Maintenance } \\
\hline Biaya gaji (Rp) & 58.260.540.- & $58.260 .540 .-$ & 58.260.540.- & $58.260 .540 .-$ \\
\hline Biaya Pemeliharaan (Rp) & 2.040.000.- & 2.040.000.- & 2.040.000.- & 2.040.000.- \\
\hline Penyusutan (Rp) & $21.100 .860 .-$ & 21.100.860.- & $21.100 .860 .-$ & 21.100.860.- \\
\hline Nilai pendapatan per tahun (Rp) & $89.399 .979 .-$ & 55.239.703.- & 38.159.565.- & 29.619.496.- \\
\hline \multicolumn{5}{|l|}{ Pajak pph 21} \\
\hline Penghasilan < 50 jt (5\%) & & & 1.907.978.- & $1,480,974 .-$ \\
\hline Penghasilan > 50 jt - 250 jt (15\%) & 13.409.996.- & $8.285 .955 .-$ & & \\
\hline Cash flow (Rp) & 75.989.982.- & 46.953.747.- & 36.251.587.- & 28,138,521.- \\
\hline Cash in flow + Penyusutan (Rp) & 97.090.842.- & 68.054.607.- & 57.352.447.- & 49,239,381.- \\
\hline NPV bunga tinggi 12\% (Rp) & 303.197.372.- & 86.312.856.- & 6.373.670.- & 54.226.415.- \\
\hline NPV bunga rendah 9\% (Rp) & 464.280.987.- & 199.222.395.- & 101.527.232.- & 27.466.743.- \\
\hline IRR (\%) & 17,65 & 14,29 & 12,20 & 10,24 \\
\hline PBP (Tahun) & 4,35 & 6,20 & 7,36 & 8,57 \\
\hline BCR (Rasio) & 1,61 & 1,13 & 0,95 & $\mathbf{0 , 8 2}$ \\
\hline
\end{tabular}

D. N. T. Budiantara: Redesain Dan Analisa Kelayakan PLTMH 25 KW... 
